\title{
The Use of Recombinant Activated Factor VII in Patients with Glanzmann's Thrombasthenia
}

\author{
Man-Chiu Poon ${ }^{1,2}$ \\ ${ }^{1}$ Department of Medicine, Pediatrics and Oncology, University of \\ Calgary Cumming School of Medicine, Calgary, Alberta, Canada \\ 2 Southern Alberta Rare Blood and Bleeding Disorders Comprehensive \\ Care Program, Foothills Medical Centre, Calgary, Alberta, Canada
}

\begin{abstract}
Address for correspondence Man-Chiu Poon, MD, Southern Alberta Rare Blood and Bleeding Disorders Comprehensive Care Program, Foothills Medical Centre, 1403-29th Street NW, Calgary, Alberta T2N 2T9, Canada (e-mail: mcpoon@ucalgary.ca).
\end{abstract}

\begin{abstract}
Keywords

- Glanzmann's thrombasthenia

- rFVIla

- integrin $\alpha 2 \mathrm{~b} \beta 3$

- bleeding

Platelet transfusion is the standard treatment to control or prevent bleeding in patients with Glanzmann's thrombasthenia (GT), but platelets are often unavailable. Recombinant activated factor VII (rFVIla) is an effective alternative to platelets in patients with GT with past/present refractoriness to platelet transfusions and antibodies to platelets. However, there is an unmet need for an alternative to platelets in patients without antibodies. This report summarizes evidence of efficacy and safety of rFVIla in patients with GT without refractoriness or antibodies to platelets from three different sources: the Glanzmann's Thrombasthenia Registry (GTR), published literature (January 01, 1999 to December 01, 2017), and the Novo Nordisk safety surveillance database. In the GTR, 133 patients received rFVIla for the treatment of 333 bleeding episodes and prevention of bleeding in 157 surgical procedures. Overall efficacy rates were 79 and $88 \%$, respectively, in patients treated for bleeding episodes or for the prevention of bleeding during surgery; effectiveness was generally similar across refractoriness/antibody status categories. Median dose per infusion of rFVIla was close to that recommended for patients with GT $(90 \mu \mathrm{g} / \mathrm{kg})$. Data from 14 published case reports also demonstrated that rFVIla is effective with an acceptable safety profile in patients with GT without antibodies to platelets. Analysis of adverse events reported in GTR and in Novo Nordisk safety surveillance database did not raise any new safety concerns. These data supported the label extension of rFVIla to include cases where platelets are not readily available, which was approved by the European Medicines Agency in December 2018.
\end{abstract}

\section{Introduction}

Glanzmann's thrombasthenia (GT) is a rare inherited bleeding disorder characterized by quantitative or qualitative defects in the platelet membrane integrin $\alpha 2 \mathrm{~b} \beta 3$ (also known as glycoprotein IIb/IIIa), resulting in abnormal platelet function. ${ }^{1}$ In addition to bleeding diathesis, loss of integrin $\alpha 2 \mathrm{~b} \beta 3$ (from ITGA2B and/or
ITGB3 mutations) and $\alpha \mathrm{v} \beta 3$ (from an ITGB3 mutation) may affect other biological processes in patients with GT. ${ }^{2}$

Patients with GT develop bleeding symptoms early in childhood. $^{3}$ In the Glanzmann's Thrombasthenia Registry (GTR), among the 187 patients with a known age of onset of bleeding, $53 \%$ had bleeding symptoms by 1 year of age and received

May 4, 2020

accepted after revision

August 25, 2020

published online

October 29, 2020
DOI https://doi.org/

$10.1055 / \mathrm{s}-0040-1718373$. ISSN 0340-6245.

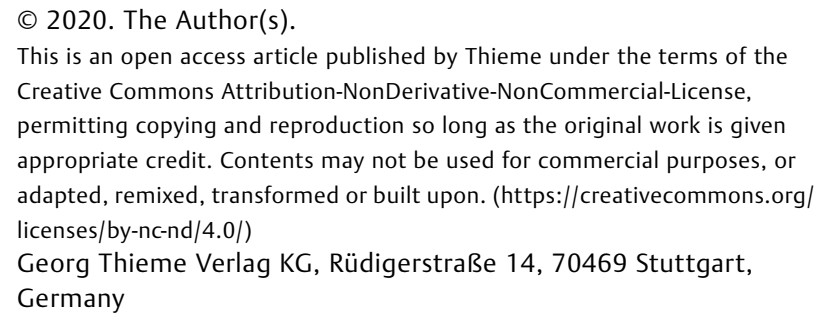


$85 \%$ by 14 years of age (median and mean ages of onset were 1 year and 5.6 years, respectively). ${ }^{4}$

Bleeding complications are typically mucocutaneous and may include epistaxis, purpura, gingival hemorrhage, and menorrhagia. Patients with GT also experience bleeding following trauma or surgical procedures, and during or after childbirth. ${ }^{1,5}$ Women of reproductive age are particularly vulnerable to bleeding, with estimated incidences of menorrhagia ranging from 74 to $98 \%{ }^{1,4}$ In a systemic review by Siddiq et al, bleeding was reported in almost half of the 40 pregnancies in 35 women, although most bleeds were mucocutaneous and relatively mild. ${ }^{6}$ In addition, primary (within 24 hours of birth) and secondary (24 hours to 12 weeks after birth) postpartum bleedings were observed in onethird and one-quarter of cases, respectively.

Bleeding episodes can often be treated by local measures and antifibrinolytics. ${ }^{5,7}$ Platelet transfusion is the standard of care if the bleeding is unresponsive to these conservative means. ${ }^{3,5}$ However, platelet transfusion has several limitations including potential for blood-borne pathogen transmission, particularly bacterial infection. ${ }^{8}$ Risk of residual viral infection with blood products is now very low, ${ }^{9}$ but emergent pathogens are a concern. ${ }^{8}$ Patients may develop antibodies to human leucocyte antigen (HLA) or integrin $\alpha 2 b \beta 3$, which can lead to platelet refractoriness, making future transfusions ineffective., ${ }^{3,5}$ In addition, platelets may not be readily available in emergencies. ${ }^{4}$ Importantly, antibodies against $\alpha 2 \mathrm{~b} \beta 3$ can cross the placenta, resulting in thrombocytopenia and bleeding in the fetus and neonates; among the 40 pregnancies reviewed by Siddiq et al, maternal alloimmunization to platelet antigens (which may occur due to exposure to $\alpha 2 \mathrm{~b} \beta 3$ platelets in fetomaternal circulation as well as by platelet transfusion) occurred in approximately three-quarters of pregnancies and was associated with four neonatal deaths. ${ }^{6}$ Therefore, there is an unmet need for a readily available alternative to platelet transfusions to avoid the risk of alloimmunization against platelets.

Recombinant activated factor VII (rFVIIa; eptacog alfa activated, NovoSeven, Novo Nordisk A/S, Bagsværd, Denmark) was approved by the European Medicines Agency (EMA) in 2004 for the treatment of bleeding episodes and for the prevention of bleeding during surgery or invasive procedures in patients with GT; but its use was limited to those with antibodies to integrin $\alpha 2 \mathrm{~b} \beta 3$ and/or HLA, and with past or present refractoriness to platelet transfusions. ${ }^{10}$

The GTR was set up as a part of an EMA regulatory commitment to collect postmarketing data on rFVIla utilization in patients with GT. Data on the use of other therapeutic options (platelets and antifibrinolytics) were also collected. ${ }^{11,12}$ In addition to the GTR, other registries and surveys on the use of rFVIIa in GT have been conducted over the past 20 years. An international survey evaluated the efficacy and safety of rFVIIa in patients with GT, most of whom had platelet antibodies or refractoriness. ${ }^{13}$ The United Statesbased Hemophilia and Thrombosis Research Society registry also collected data on the use of rFVIIa in patients with GT and other platelet disorders. ${ }^{14}$
Data from the registries and survey indicate that physicians use rFVIIa to prevent bleeding cases irrespective of platelet antibodies and/or platelet refractoriness. ${ }^{11-13}$ In the international survey, prevention of antiplatelet alloimmunization was cited as one of the reasons to use rFVIIa in $43 \%$ of cases. ${ }^{13}$ However, there is a need for data to support the efficacy and safety of rFVIIa in patients without platelet antibodies, without refractoriness to platelets and in cases when platelets are not readily available.

This article reports data from the GTR, a literature review, and the Novo Nordisk safety surveillance database, and evaluates the efficacy and safety of rFVIIa in patients with GT without antibodies or refractoriness to platelets using these three data sources. These data were used to provide the required evidence to support the label extension for the use of rFVIIa in cases where platelets are not readily available.

\section{Methods}

\section{The Glanzmann's Thrombasthenia Registry}

The GTR is a prospective, postmarketing, observational, multinational web-based registry (NCT01476423) designed to allow the collection of data for the evaluation of efficacy and safety of rFVIIa and other hemostatic agents used in patients with GT for the treatment of severe bleeding episodes or the prevention of bleeding during surgery. ${ }^{11,12}$

Data entry into the GTR was from May 10, 2007 to December 16, 2011. Overall, data collected from 218 patients with GT treated for 870 bleeding episodes and 204 surgical procedures were used for primary effectiveness analysis. The secondary effectiveness analysis was performed using data from 829 bleeding episodes and 206 surgical procedures. ${ }^{11,12}$ Bleeding subtypes $^{12}$ and the most prevalent minor and major procedures ${ }^{11}$ have been reported previously.

Full inclusion and exclusion criteria were listed previously. ${ }^{11,12}$ In brief, patients (males and females of any age) with a diagnosis of congenital GT were included in the GTR. Refractoriness to platelets or the presence of antibodies was assessed initially and at specific intervals at the discretion of the investigator. Dosing was according to local treatment practice and there were no set treatment protocols. Full details on data handling are published elsewhere. ${ }^{11,12}$

Data from a subset of patients $(N=133)$ from the GTR who received rFVIIa, alone or in combination with other hemostatic agents or platelets, were used to evaluate the efficacy and safety of rFVIIa in the present analysis.

\section{Definitions}

Refractoriness to platelet transfusion was defined clinically as persistence of bleeding, or rebleeding within 24 hours, or bleeding during surgery despite an adequate number of platelet infusions (as determined by the clinician). A patient's refractoriness and antibody status were both categorized as "positive" (indicates at least one positive answer at any admission), "negative" (indicates no positive answers, but at least one negative) or "unknown" (indicates only 
unknown or missing answers). As a result of these categories, a nine-level classification was used on a per-patient basis in relation to refractoriness and antibody status; refractoriness was categorized as positive, negative, or unknown, with each category subclassified according to the antibody status (positive, negative, or unknown).

Definitions used for treatment effectiveness during bleeding episodes and surgery are shown in -Supplementary Table S1 (available in the online version).

\section{Analysis of Efficacy and Safety}

Analysis of efficacy was based on all treatment-allocated patients for whom information on efficacy end points was available. Efficacy evaluations were summarized by age $(<12$ years; $12-17$ years; $\geq 18$ years), refractoriness and antibodies to platelets status (positive, negative, or unknown), and treatment group: rFVIIa alone (N7); rFVIIa with platelets and other hemostatic treatment ( $\mathrm{N} 7 \mathrm{POH}$, where $\mathrm{P}=$ platelets, $\mathrm{OH}=$ other hemostatic treatment, mostly antifibrinolytics); rFVIIa with other hemostatic treatment (N7OH); rFVIla with platelets (N7P). All treatment episodes were included in the analysis of safety. Due to the observational nature of data, descriptive statistics were used to summarize the data and no formal statistical comparisons were performed.

\section{Published Literature/Case Reports}

A literature search for English language publications from January 01, 1999 to December 01, 2017 was performed by Novo Nordisk Global Information and Analysis using BIOSIS Previews, Current Contents Search, Embase, and MEDLINE. Detailed search criteria and number of hits identified using these criteria are shown in -Supplementary Table $\mathbf{S 2}$ (available in the online version). All GT cases of treatment and prevention of bleedings (during delivery and surgery) in all ages and both sexes during the reported period were included. Cases without antibodies to $\alpha 2 \mathrm{~b} \beta 3$ and/or HLA and without past or present refractoriness to platelet transfusions were described. Literature was selected avoiding an overlap with the GTR and Novo Nordisk safety database. Data from published literature and case reports were used to evaluate the efficacy of rFVIIa in patients with GT.

\section{Novo Nordisk Safety Surveillance Database}

Safety data from the use of rFVIIa in patients with GT were collected in the Novo Nordisk safety database. Included safety data were obtained from spontaneous reports, solicited reports from postauthorization studies and registries, and adverse events (AEs) reported in the published literature. Data from the Novo Nordisk safety database were used to evaluate the safety of rFVIIa in patients with GT.

\section{Results}

\section{The Glanzmann's Thrombasthenia Registry}

Patients and Demographic Characteristics

Overall, 133 patients (N7, $n=62$; N7POH, $n=45$; N7OH, $n=85$; N7P, $n=11$ ) were treated with rFVIIa in 492 admis- sions during the observational period from May 10, 2007 to December 16, 2011. Among these, 94 patients were treated with rFVIIa for 333 bleeding episodes and 77 patients received rFVIIa for the prevention of bleeding during 159 surgical procedures. No noticeable differences in demographic characteristics were observed between the four treatment groups ( - Table $\mathbf{1}$ ). In addition, no apparent differences were observed between patients treated for bleeding and those undergoing surgery (data not shown) except for mean age, which was slightly younger for patients treated for bleeding (21.0 years) than those undergoing surgery (28.5 years).

The pattern of refractoriness and antibody status was similar across the four treatment groups ( - Supplementary Table 53, available in the online version) and between age groups (- Supplementary Table S4, available in the online version). However, the number of patients in the N7P treatment group was low (11 of the 133 patients) compared with the number of patients in the other treatment groups. It should also be noted that the number of patients in the 12 to 17 years age group was low (19 patients) compared with the other age groups ( 41 and 77 patients in the $<12$ years and $\geq 18$ years age groups, respectively).

\section{Dosing of rFVlla}

Although there was large variation, the median dose per infusion of rFVIIa in patients with bleeding episodes was $90 \mu \mathrm{g} / \mathrm{kg}$, which is in line with the recommended dose for patients with GT (90 [range: $80-120] \mu g / k g)$. Median dose per infusion was similar across all four treatment groups ( - Table 2). When assessed by refractoriness and antibody status, median dose per infusion was $90 \mu \mathrm{g} / \mathrm{kg}$ in all but two patient categories (-Table 2). The median dose per infusion was slightly lower $(78 \mu \mathrm{g} / \mathrm{kg}$ ) in patients with unknown refractoriness/unknown antibody status than in other categories, but there were only four admissions for patients with this status.

Similar to the dosing in patients with bleeding episodes, there was a large variation in the dose per infusion of rFVIIa among patients treated for prevention of bleeding during surgery; however, the median dose per infusion $(92 \mu \mathrm{g} / \mathrm{kg})$ was similar in all four treatment groups, ranging from 90 to $95 \mu \mathrm{g} / \mathrm{kg}$ (-Table 3). Regardless of refractoriness or antibody status, the median dose per infusion administered for the prevention of bleeding during surgical procedures was generally similar across categories ( - Table 3 ); median doses were mostly close to or slightly higher than $90 \mu \mathrm{g} / \mathrm{kg}$, except for patients with refractoriness to platelets but without antibodies, for whom the median dose per infusion was higher than those of other groups $(142 \mu \mathrm{g} / \mathrm{kg})$. A large variation in total dose of rFVIIa and duration of treatment was seen across these categories.

\section{Evaluation of rFVIla Efficacy}

Glanzmann's Thrombasthenia Registry

In all patients admitted for bleeding episodes, treatment with rFVIIa-based regimens was evaluated as effective in $79 \%$ 
Table 1 Summary of demography and patient history for patients treated with rFVIla in the GTR

\begin{tabular}{|c|c|c|c|c|c|c|}
\hline Characteristics & & N7 $(N=62)$ & $\begin{array}{l}\text { N7POH } \\
(N=45)\end{array}$ & $\mathrm{N7OH}(N=85)$ & N7P $(N=11)$ & All $^{\mathrm{a}}(N=133)$ \\
\hline \multirow[t]{3}{*}{ Age at first admission, $\mathrm{y}^{\mathrm{b}}$} & $N$ & 61 & 45 & 84 & 11 & 131 \\
\hline & Mean (SD) & $23.3(16)$ & $20.8(19)$ & $22.9(17)$ & $18.4(17)$ & $24.1(18)$ \\
\hline & Range & $1-64$ & $0-80$ & $1-80$ & $2-64$ & $0-80$ \\
\hline \multirow[t]{4}{*}{ Age at first admission, $n(\%)$} & $<12 y$ & $17(27)$ & $20(44)$ & $26(31)$ & $5(45)$ & $41(31)$ \\
\hline & $12-17 y$ & $7(11)$ & $4(9)$ & $10(12)$ & $1(9)$ & $16(12)$ \\
\hline & $\geq 18 y$ & $37(60)$ & $21(47)$ & $48(56)$ & $5(45)$ & $74(56)$ \\
\hline & Not reported & $1(2)$ & 0 & $1(1)$ & 0 & $2(2)$ \\
\hline \multirow[t]{2}{*}{ Sex, $n(\%)$} & Female & $36(58)$ & $24(53)$ & $48(56)$ & $8(73)$ & $75(56)$ \\
\hline & Male & $26(42)$ & $21(47)$ & $37(44)$ & $3(27)$ & $58(44)$ \\
\hline \multirow[t]{6}{*}{ Ethnic origin, $n(\%)$} & African & $4(6)$ & $1(2)$ & $3(4)$ & 0 & $6(5)$ \\
\hline & Asian & $4(6)$ & $5(11)$ & $9(11)$ & $1(9)$ & $14(11)$ \\
\hline & Caucasian & $30(48)$ & $29(64)$ & $45(53)$ & $9(82)$ & $72(54)$ \\
\hline & Middle Eastern & $1(2)$ & $1(2)$ & $1(1)$ & 0 & $1(1)$ \\
\hline & Other & $4(6)$ & $3(7)$ & $3(4)$ & $1(9)$ & $10(8)$ \\
\hline & Unknown & $19(31)$ & $6(13)$ & $24(28)$ & 0 & $30(23)$ \\
\hline \multirow[t]{4}{*}{ Disease type, ${ }^{\complement} n(\%)$} & Type I & $30(48)$ & $18(40)$ & $49(58)$ & $3(27)$ & $62(47)$ \\
\hline & Type II & $7(11)$ & $4(9)$ & $7(8)$ & $2(18)$ & $13(10)$ \\
\hline & Variant & $2(3)$ & $1(2)$ & $2(2)$ & 0 & $3(2)$ \\
\hline & Unknown & $23(37)$ & $22(49)$ & $27(32)$ & $6(55)$ & $55(41)$ \\
\hline
\end{tabular}

Abbreviations: GPIIb-IIla, glycoprotein IIb-IIla; GTR, Glanzmann's thrombasthenia Registry; N7, rFVIla alone; N7OH, rFVIla + other hemostatic treatment; N7P, rFVIIa + platelets; N7POH, rFVIla + platelets + other hemostatic treatment; rFVIla, recombinant activated factor VII; SD, standard deviation.

aPatients who changed therapy during the study period or had both surgeries and bleedings, have been counted in several groups; therefore, the number of patients in each group does not sum up to the total.

'There were two patients (four admissions) $\geq 65$ years of age; one was 80 and one was 73 years of age.

'The disease is classified based on the level of platelet $\alpha 2 b \beta 3$ (GPIIb-IIIa) complexes present: type I (less than $5 \%$ of normal GPIIb-IIIa levels), type II (5-20\% of normal GPIIb-IIla levels), variant-type (the level of GPIIb-Illa is above 20\%; however, the proteins are dysfunctional) or disease type not reported (unknown).

(262/333) of admissions. In each treatment group, treatment was evaluated to be effective in most (65-86\%) of the admissions (-Fig. 1A). Regardless of refractoriness and antibody status, treatment was evaluated to be effective in most of the admissions (range: $56-100 \%$ ) across the categories (-Supplementary Table 55, available in the online version). Overall, treatment with rFVIla-based regimens during surgery was evaluated as effective in $88 \%(140 / 159)$ of admissions. In each treatment group, treatment was effective in most of the admissions (range: 68-100\%; - Fig. 1B). Regardless of refractoriness and antibody status, treatment was evaluated as effective in most admissions (range: 67100\%) across the categories (-Supplementary Table S5, available in the online version).

Irrespective of age, most admissions were evaluated to be effective (data not shown). Although not included as a predefined age group, only two patients (four admissions) were aged $\geq 65$ years ( 73 and 80 years of age); treatment was considered effective and uneventful in these patients.

\section{Published Literature}

Overall, 143 references, including full articles and congress abstracts, met the search criteria and were reviewed. After full-text assessment, 14 references that contained sufficient predefined assessments of efficacy were included and evaluated. ${ }^{6,13,15-26}$ These references included 31 cases without antibodies to integrin or refractoriness to platelets, or for which the status of antibodies/refractoriness was unknown (-Supplementary Table 56, available in the online version). Out of these, efficacy and safety of rFVIla were reported for 30 cases. These patients received treatment with rFVIIa or other hemostatic agents for the treatment of bleeding episodes and to prevent bleeding during surgery. In summary, published literature and case reports showed that a treatment regimen of rFVIIa alone, or based mainly on rFVIIa, reduces platelet transfusions, was effective for bleeding treatment or prophylaxis, and had an acceptable safety profile in patients with GT without antibodies to platelets, or where platelets are not readily available. ${ }^{13,15-26}$ 
Table 2 Dosing of rFVIla in bleeding episodes by treatment and by refractoriness and antibody status in the GTR

\begin{tabular}{|c|c|c|c|c|c|c|c|}
\hline & $\begin{array}{l}\text { Total number } \\
\text { of admissions }\end{array}$ & $\begin{array}{l}\text { Total } \\
\text { number } \\
\text { of doses }^{\text {a }}\end{array}$ & $\begin{array}{l}\text { No. of doses per } \\
\text { admission, }{ }^{\mathrm{a}} \text { median } \\
\text { (range) }\end{array}$ & $\begin{array}{l}\text { Dose per } \\
\text { infusion } \\
(\mu \mathrm{g} / \mathrm{kg}) \text {, } \\
\text { median } \\
\text { (range) }\end{array}$ & $\begin{array}{l}\text { Total dose per } \\
\text { admission }(\mu \mathrm{g} / \mathrm{kg}) \text {, } \\
\text { median (range) }\end{array}$ & $\begin{array}{l}\text { Interval } \\
\text { between } \\
\text { doses }(\mathrm{h}) \text {, }^{\mathrm{b}} \\
\text { median } \\
\text { (range) }\end{array}$ & $\begin{array}{l}\text { Duration of } \\
\text { treatment }(h),{ }^{b} \\
\text { median (range) }\end{array}$ \\
\hline All patients & $327^{c}$ & 972 & $2.0(1.0-10.0)$ & $90(28-450)$ & $180(28-6260)$ & $3.0(1.0-168.0)$ & $8.0(1.5-338.5)$ \\
\hline \multicolumn{8}{|l|}{ Treatment group } \\
\hline N7 & 154 & 295 & $1.0(1.0-10.0)$ & $90(48-272)$ & $90(48-1260)$ & $3.0(1.0-68.0)$ & $4.0(1.5-168.0)$ \\
\hline $\mathrm{N7POH}$ & 54 & 244 & $3.0(1.0-10.0)$ & $90(36-450)$ & $285(40-6260)$ & $3.0(1.0-168.0)$ & $26.0(2.0-338.5)$ \\
\hline $\mathrm{N7OH}$ & 106 & 394 & $3.0(1.0-10.0)$ & $90(28-300)$ & $270(28-6000)$ & $3.0(1.0-107.0)$ & $12.5(2.0-227.0)$ \\
\hline N7P & 13 & 39 & $2.0(1.0-10.0)$ & $90(81-288)$ & $243(90-900)$ & $3.0(1.0-24.0)$ & $4.0(2.0-48.0)$ \\
\hline \multicolumn{8}{|c|}{ Refractoriness and antibody status } \\
\hline Refr POS/AB POS & 36 & 125 & $3.0(1.0-10.0)$ & $90(40-450)$ & $278(40-4230)$ & $3.0(2.0-168.0)$ & $9.0(2.0-240.0)$ \\
\hline Refr POS/AB NEG & 31 & 177 & $5.0(1.0-10.0)$ & $90(37-160)$ & $574(90-6260)$ & $3.0(1.0-114.0)$ & $25.5(2.0-338.5)$ \\
\hline Refr POS/AB UNK & 6 & 40 & $7.0(3.0-10.0)$ & $90(90-90)$ & $630(270-1260)$ & $3.0(2.0-68.0)$ & $27.0(4.0-168.0)$ \\
\hline Refr NEG/AB POS & 43 & 172 & $3.0(1.0-10.0)$ & $96(28-300)$ & $270(28-2760)$ & $3.0(2.0-25.0)$ & $17.0(2.0-72.0)$ \\
\hline Refr NEG/AB NEG & 157 & 257 & $1.0(1.0-10.0)$ & $90(34-290)$ & $90(40-900)$ & $3.0(1.0-24.0)$ & $4.0(1.5-72.0)$ \\
\hline Refr NEG/AB UNK & 9 & 41 & $4.0(2.0-9.0)$ & $90(26-111)$ & $270(72-810)$ & $4.0(2.0-57.0)$ & $28.5(3.0-136.0)$ \\
\hline Refr UNK/AB POS & 14 & 66 & $3.0(1.0-10.0)$ & $90(62-360)$ & $330(90-1180)$ & $4.0(2.0-42.0)$ & $52.0(32.0-93.0)$ \\
\hline Refr UNK/AB NEG & 27 & 87 & $3.0(1.0-10.0)$ & $90(70-170)$ & $270(80-1020)$ & $3.0(1.0-30.0)$ & $4.8(2.0-68.0)$ \\
\hline Refr UNK/AB UNK & 4 & 7 & $1.0(1.0-4.0)$ & $78(78-128)$ & $125(96-312)$ & $18.0(3.0-19.0)$ & $39.5(39.5-39.5)$ \\
\hline
\end{tabular}

Abbreviations: AB, antibody; GTR, Glanzmann's Thrombasthenia Registry; N7, rFVIla alone; N7OH, rFVIla + other hemostatic treatment; N7P, rFVIla + platelets; N7POH, rFVIla + platelets + other hemostatic treatment; NEG, negative; POS, positive; Refr, refractoriness; rFVIla, recombinant activated factor VII; UNK, unknown.

${ }^{a}$ The doses of rFVlla were reported as single dose per infusion, with date and time for the first 10 records. In cases with more than 10 records, only the total amount of the additional doses was collected. The number of additional doses was not recorded. Therefore, the maximum number of doses per admission is 10. bonly calculated for admissions with more than one dose and with date and time of dose recorded.

'Six admissions had missing dose details and they are not included in this table.

\section{Evaluation of rFVIla Safety in Patients with GT}

\section{Glanzmann's Thrombasthenia Registry}

In the GTR, a total of 15 AEs were reported in nine patients; of these, seven were serious AEs. No deaths were reported in patients receiving rFVIIa (-Table 4). Two patients treated with rFVIIa had AEs that were assessed by the investigator as "possibly/probably" related to rFVIIa: "nausea," "dyspnea," and "headache" in one patient (nonserious) and "deep vein thrombosis" (DVT) in one patient (serious). All other AEs and serious AEs were considered unlikely to be related to rFVIIa. The DVT occurred in a 25-year-old woman who received 19 doses of rFVIIa $142 \mu \mathrm{g} / \mathrm{kg}$ at 2 - to 3-hour intervals (along with platelets 3 units and red blood cells 5 units) to prevent bleeding during an emergency laparotomy; treatment was considered partially effective. She presented with a DVT 5 days after the last dose of rFVIIa was administered and remained in hospital 14 days postoperatively. The surgery and its associated immobilization may have been confounding etiological factors for the DVT.
Analysis of the AEs reported in the GTR showed no new safety concerns. No differences were observed in the type or severity of AEs between patients with or without refractoriness or antibodies to platelets.

\section{Novo Nordisk Safety Surveillance Database}

Since the first approval of rFVIIa in the GT indication in 2004, 53 cases comprising 77 AEs ( 43 serious events) were cumulatively reported from postmarketing sources in the Novo Nordisk safety database up to December 01, 2017. Based on the cumulative experience with rFVIIa, the number of AEs for each of the important identified risks relevant for treatment with rFVIIa in GT is shown in - Table 5. In total, 42 AEs (24 serious) concerned important identified risks associated with rFVIIa treatment. Analysis of these cases did not raise any safety concerns.

Among the 53 cases, six case reports had a fatal outcome. Three patients had fatal hemorrhagic events (vaginal $[n=1]$, site not defined $[n=1]$, cerebral $[n=1])$. The patient with cerebral hemorrhage also had disseminated intravascular 
Table 3 Dosing of rFVIla in surgical cases by treatment and by refractoriness and antibody status in the GTR

\begin{tabular}{|c|c|c|c|c|c|c|c|}
\hline & $\begin{array}{l}\text { Total } \\
\text { number } \\
\text { of } \\
\text { admissions }\end{array}$ & $\begin{array}{l}\text { Total } \\
\text { number } \\
\text { of doses }^{\text {a }}\end{array}$ & $\begin{array}{l}\text { No. of doses per } \\
\text { admission, } \\
\text { median (range) }\end{array}$ & $\begin{array}{l}\text { Dose per infusion } \\
(\mu \mathrm{g} / \mathrm{kg}) \text {, } \\
\text { median (range) }\end{array}$ & $\begin{array}{l}\text { Total dose per } \\
\text { admission }(\mu \mathrm{g} / \mathrm{kg}) \text {, } \\
\text { median (range) }\end{array}$ & $\begin{array}{l}\text { Interval } \\
\text { between doses (h), } \\
\text { median (range) }\end{array}$ & $\begin{array}{l}\text { Duration of } \\
\text { treatment (h), } \\
\text { median (range) }\end{array}$ \\
\hline All patients & $157^{c}$ & 720 & $3.0(1.0-24.0)$ & $92(4-270)$ & $270(4-8544)$ & $3.0(1.0-749.0)$ & $5.0(1.5-749.0)$ \\
\hline \multicolumn{8}{|l|}{ Treatment group } \\
\hline N7 & 62 & 210 & $2.5(1.0-21.0)$ & $90(70-250)$ & $270(80-6336)$ & $2.0(2.0-264.0)$ & $4.0(1.5-264.0)$ \\
\hline N7POH & 21 & 134 & $3.0(1.0-22.0)$ & $90(4-200)$ & $270(4-4617)$ & $3.0(1.0-18.0)$ & $5.3(2.0-139.0)$ \\
\hline $\mathrm{N7OH}$ & 70 & 331 & $3.0(1.0-22.0)$ & $95(25-270)$ & $305(90-8544)$ & $3.0(1.0-749.0)$ & $5.5(1.5-749.0)$ \\
\hline N7P & 4 & 45 & $8.5(4.0-24.0)$ & $90(90-90)$ & $765(360-2167)$ & $3.0(1.0-12.0)$ & $25.0(8.0-126.0)$ \\
\hline \multicolumn{8}{|c|}{ Refractoriness and antibody status ${ }^{d}$} \\
\hline Refr POS/AB POS & 40 & 120 & $3.0(1.0-7.0)$ & $102(70-250)$ & $300(85-1250)$ & $2.0(2.0-26.0)$ & $4.0(1.5-68.0)$ \\
\hline Refr POS/AB NEG & 12 & 65 & $3.0(1.0-20.0)$ & $142(85-200)$ & $315(90-4617)$ & $2.0(2.0-12.0)$ & $6.0(4.0-59.0)$ \\
\hline Refr POS/AB UNK & 1 & 11 & $11.0(11.0-11.0)$ & $90(90-90)$ & $990(990-990)$ & $3.0(1.0-6.0)$ & $28.0(28.0-28.0)$ \\
\hline Refr NEG/AB POS & 24 & 140 & $3.0(1.0-22.0)$ & $93(4-270)$ & $418(4-5954)$ & $3.0(1.0-13.0)$ & $7.0(1.5-102.0)$ \\
\hline Refr NEG/AB NEG & 36 & 178 & $3.0(1.0-22.0)$ & $90(28-180)$ & $270(80-6336)$ & $3.0(1.0-749.0)$ & $4.8(2.0-749.0)$ \\
\hline Refr NEG/AB UNK & 1 & 24 & $24.0(24.0-24.0)$ & 90 (90-90) & $2167(2167-2167)$ & $4.5(1.0-12.0)$ & $126(126.0-126.0)$ \\
\hline Refr UNK/AB POS & 20 & 84 & $3.0(1.0-21.0)$ & $95(25-240)$ & $354(90-1988)$ & $4.0(2.0-264.0)$ & $6.5(2.5-264.0)$ \\
\hline Refr UNK/AB NEG & 23 & 98 & $2.0(1.0-20.0)$ & $90(90-180)$ & $180(90-8544)$ & $2.0(1.0-30.0)$ & $5.0(2.5-97.5)$ \\
\hline
\end{tabular}

Abbreviations: AB, antibody; GTR, Glanzmann's Thrombasthenia Registry; N7, rFVIla alone; N7OH, rFVIla + other hemostatic treatment; N7P, rFVIla + platelets; N7POH, rFVIla + platelets + other hemostatic treatment; NEG negative; POS, positive; Refr, refractoriness; rFVIla, recombinant activated factor VII; UNK, unknown.

${ }^{a}$ The doses of rFVlla used prior, during, and after a surgery were reported as single dose per infusion, with date and time for the first 20 records. In cases with more than 20 records, only the total amount of the additional doses was collected. The number of additional doses was not recorded. The maximum number of doses per admission is three times 20 (prior, during, and after).

${ }^{b}$ Only calculated for surgeries with more than one dose, and with date and time of dose recorded. The dose interval at 749.0 is probably an outlier most likely due to an error in indication of timing of dosing.

${ }^{\mathrm{T}}$ Two admissions had missing dose details, and they are not included in this table.

${ }^{\mathrm{d}}$ There were no admissions in the UNK/UNK category.

coagulation, thrombocytopenia, postoperative renal failure, and thrombosis; a further patient had atrial thrombosis. Intestinal ischemia was another fatal event, and no information was available on the sixth case. Analysis of the fatal cases showed no new safety concerns regarding the use of rFVIIa.

Only 11 cases had information on refractoriness and/or antibodies to platelets ( - Supplementary Table 57, available in the online version). Due to the low number of cases with this information (11/53 cases), a comparison between the patients with and without refractoriness and/or antibodies to platelets was not possible. However, no difference was observed in the type and severity of AEs between the patients with information on refractoriness and/or antibodies to platelets and the group of patients without this information.

There were five cases with thromboembolic events reported; two of these were in patients aged $\geq 65$ years. One of these events was reported in the literature and involved a 72-year-old woman who underwent abdominal surgery for gastrointestinal bleeding and received rFVIIa $(30 \mu \mathrm{g} / \mathrm{kg})$ at a high continuous rate over a prolonged period. ${ }^{13,27}$ In addition, the surgery and its associated immobilization may have been confounding factors for the thromboembolic event.

\section{Discussion}

Data collected from the GTR, published literature, and Novo Nordisk safety surveillance database report the consistent efficacy and safety profile of rFVIIa in patients with GT. Similar efficacy across patient categories regardless of refractoriness or antibody status supports the label extension of use of rFVIIa in patients with GT where platelets are not readily available. Dosing of rFVIIa in this analysis was close to the recommended and approved dose regimen of rFVIIa in GT $(90 \mu \mathrm{g} / \mathrm{kg}$ [range: $80-120 \mu \mathrm{g}$ ]) at intervals of 2 hours (1.52.5 hours) for bleeding episodes and surgical cases.

When conservative means are ineffective, use of platelets is currently considered the standard of care for the treatment or prevention of bleeding in patients with GT. However, use of platelets is associated with several limitations, including risk of pathogen transmission, development of antibodies, 

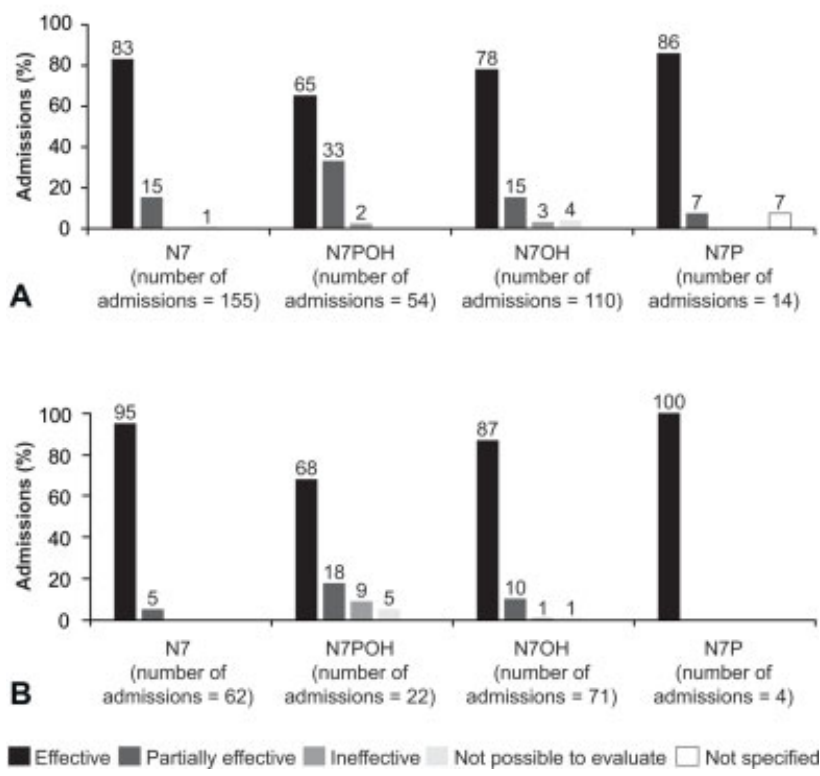

Fig. 1 Efficacy of rFVIla alone or in combination with other hemostatic treatment or platelets in patients with GT in the GTR. Efficacy of rFVIla alone or in combination with other treatment for the (A) treatment of bleeding episodes in patients with GT. (B) Prevention of bleeding during surgery in patients with GT. GT, Glanzmann's thrombasthenia; GTR, Glanzmann's Thrombasthenia Registry; N7, rFVIla alone; N7OH, rFVIla + other hemostatic treatment; N7P, rFVIIa + platelets; N7POH, rFVIIa + platelets + other hemostatic treatment; rFVIla, recombinant activated factor VII.

and refractoriness to platelets. In addition, platelets may not be immediately or readily available in all clinics. ${ }^{28}$

The data presented here support the applicability of rFVIIa as a good alternative treatment to platelet transfusions for severe bleeding episodes. Overall, treatment effectiveness in N7 and N7OH groups was similar to that in N7P and N7POH

Table 4 Summary of adverse events in the GTR (treatments including rFVIla)

\begin{tabular}{|l|l|l|l|}
\hline & $\begin{array}{l}\text { Number of } \\
\text { patients } \\
(N=133)\end{array}$ & $\begin{array}{l}\text { Number of } \\
\text { admissions } \\
(N=492)\end{array}$ & $\begin{array}{l}\text { Number of } \\
\text { adverse } \\
\text { events }\end{array}$ \\
\hline $\begin{array}{l}\text { All adverse } \\
\text { events, } n\end{array}$ & 9 & 11 & 15 \\
\hline Serious, $n$ & 4 & 5 & $7^{\text {a }}$ \\
\hline Nonserious, $n$ & 6 & 6 & 8 \\
\hline
\end{tabular}

Abbreviations: GTR, Glanzmann's Thrombasthenia Registry; N7, rFVIla alone; N7OH, rFVIla + other hemostatic treatment; N7POH, rFVIIa + platelets + other hemostatic treatment; rFVIla, recombinant activated factor VII.

${ }^{a}$ Serious events (treatment group) were septicemia (N7POH), respiratory insufficiency (N7POH), cardiac decompensation (N7POH), subarachnoideal bleeding (N7POH), rebleeding, and hematoma due to a fall (N7), deep vein thrombosis (N7POH), and rectorrhagia (N7OH).
Table 5 Important identified risks and number of adverse events in GT (postmarketing, including serious adverse events from the GTR)

\begin{tabular}{|l|l|l|l|}
\hline Adverse events & $\begin{array}{l}\text { Number } \\
\text { of } \\
\text { serious } \\
\text { adverse } \\
\text { events }\end{array}$ & $\begin{array}{l}\text { Number of } \\
\text { nonserious } \\
\text { adverse } \\
\text { events }\end{array}$ & Total \\
\hline $\begin{array}{l}\text { Arterial thromboembolic } \\
\text { events }\end{array}$ & 1 & 0 & 1 \\
\hline $\begin{array}{l}\text { Venous thromboembolic } \\
\text { events }\end{array}$ & 9 & 0 & 9 \\
\hline $\begin{array}{l}\text { Mixed thromboembolic } \\
\text { events }\end{array}$ & 4 & 1 & 5 \\
\hline Lack of efficacy & 7 & 17 & 24 \\
\hline Allergic reactions ${ }^{\mathrm{a}}$ & 3 & 0 & 3 \\
\hline Total & 24 & 18 & 42 \\
\hline
\end{tabular}

Abbreviations: GT, Glanzmann's thrombasthenia; GTR, Glanzmann's Thrombasthenia Registry; N7POH, rFVIla + platelets + other hemostatic treatment.

Note: There were two fatal outcomes associated with these adverse events. One patient had a venous thromboembolic event (pulmonary embolism), co-reported with two mixed thromboembolic events ("atrial thrombosis" and "intracardial thrombus"). The second patient had mixed thromboembolic events ("disseminated intravascular coagulation" and "thrombosis"). In the GTR, there was one serious adverse event of deep vein thrombosis, which occurred in the N7POH treatment group.

${ }^{a}$ MedDRA narrow scope terms only.

groups; therefore, the addition of platelets to rFVIla given with or without other hemostatic agents did not generally improve treatment effectiveness. Furthermore, in patients with a "negative" refractoriness and antibody status, rFVIIa showed similar efficacy (\% effective admissions) to that observed in patients with a "positive" refractoriness and antibody status in bleeding episodes (85\% [negative category] vs. $72 \%$ [positive category]) and surgical cases (95\% [negative category] vs. 95\% [positive category]). Of note, these efficacy data differ slightly to those included in the EMA Summary of Product Characteristics ${ }^{29}$ (- Supplementary Table 58, available in the online version) due to differences in patient categorization.

Previous analyses of GTR data suggest that the effectiveness of rFVIIa is similar to that of platelet-based treatment in patients without refractoriness or antibodies. ${ }^{11,12}$ This indicates the validity of rFVIIa use in all patients with GT, irrespective of refractoriness/antibodies to platelets status. There were also no relevant differences between the effectiveness and safety of rFVIIa in adults and children. ${ }^{30}$ Only two patients in the GTR were $\geq 65$ years of age; treatments including rFVIIa were considered effective in $4 / 4$ admissions in these patients, with no AEs reported. However, given the limited patient numbers, we are unable to make any conclusions regarding response in patients $\geq 65$ years of age compared with younger age groups. 
Use of rFVIIa offers several benefits over platelet transfusion. There is no need for time-consuming and difficult assessments of antibody or refractoriness status in emergency situations. rFVIIa is not associated with the risk of bloodborne pathogen transmission. Furthermore, rFVIIa prevents the risk of alloimmunization and refractoriness associated with platelet transfusions. This is particularly important in women of reproductive age with GT, where there is a substantial risk of transfer of alloantibodies to the fetus via the placenta following platelet transfusions, resulting in potentially fatal neonatal bleeding.

As a hemostatic agent, rFVIIa is associated with some potential risks that include thromboembolic events, lack of efficacy, and allergic reactions. In patients treated with rFVIIa in the GTR, there was a low rate of thrombosis (1/ 133 patients) and allergic reactions (1/133 patients). Reported lack of effectiveness of rFVIIa in patients in the GTR was very low $(\sim 1.4 \%)$. Thromboembolic events, lack of efficacy, and allergic reactions were, however, identified in the postmarketing database. In patients with hemostatic deficiency and presence of thromboembolic risk factors, thromboembolic events may occur when a hemostatic agent such as rFVIIa is used to normalize hemostasis. The overall incidence of thromboembolic events with rFVIIa was low and in line with what has been reported previously in patients with GT. ${ }^{31}$ Importantly, data from all the available sources included in the present study did not raise any new safety concerns or suggest a difference in thromboembolic risk between patients with and without refractoriness or antibodies to platelets.

\section{Limitations}

Owing to the observational design of the GTR, it is difficult to compare efficacy and safety outcomes between groups. The data (dosage and treatment parameters) from the literature and postmarketing database are heterogeneous in nature; dosing in all cases was according to local practice. However, it is challenging to collect data from large randomized controlled trials due to the rarity of GT. Therefore, data from the sources included in the present study provide valuable evidence on efficacy and safety of rFVIIa in GT.

In the GTR, coding of refractoriness/antibody status was performed at first admission or at the discretion of the investigator. In the other data sources used in the present analysis, antibody or refractoriness status was not always reported. Lack of documentation of antibody/refractoriness status at the time of each episode limits the analysis.

The number of AEs reported in the GTR was low, limiting analysis between patients with or without refractoriness or antibodies to platelets. In addition, there were only a few cases from the Novo Nordisk safety database with available information on refractoriness and/or antibodies to platelets, limiting comparisons between categories.

\section{Conclusion}

The effectiveness of rFVIIa was demonstrated in the GTR and published literature. The use of rFVIIa was reported in patients with GT without antibodies to platelets, and in patients without refractoriness. As a result of these data, the European label for rFVIla has been extended to include patients with GT with past or present refractoriness to platelet transfusions, or where platelets are not readily available.

\section{What is known about this topic?}

- Recombinant activated factor VII (rFVIIa) was first approved in Europe in 2004 for the treatment of bleeding episodes and prevention of bleeding during surgery or invasive procedures in patients with Glanzmann's thrombasthenia (GT).

- The indication for rFVIIa was previously limited to patients with antibodies to integrin $\alpha 2 \mathrm{~b} \beta 3$ (glycoprotein IIb/IIIa) and/or human leukocyte antigen and with past or present refractoriness to platelet transfusions.

\section{What does this paper add?}

- Here we report the use and effectiveness of rFVIIa treatment in patients with GT, irrespective of antiplatelet antibodies and/or platelet refractoriness status.

- This analysis of the literature showed that rFVIIa has an acceptable safety profile and is effectively used as an alternative to platelet transfusions.

Funding

This work was supported by Novo Nordisk.

Conflict of Interest

M.-C.P. was chair of Novo Nordisk's expert panel on the Glanzmann's Thrombasthenia Registry; has been an ad hoc speaker for Bayer, Novo Nordisk, and Pfizer; attended advisory board meetings of Bioverativ/Sanofi, CSL Behring, Novo Nordisk, Pfizer, Roche, and Takeda; and received grant funding from Bayer and CSL Behring.

Acknowledgments

Soraya Benchikh el Fegoun (Novo Nordisk) provided valuable input. Editorial assistance was provided by Leanne Regan and Sindhu Doppalapudi, of Fishawack Communications $\mathrm{GmbH}$, funded by Novo Nordisk.

\section{References}

1 George JN, Caen JP, Nurden AT. Glanzmann's thrombasthenia: the spectrum of clinical disease. Blood 1990;75(07):1383-1395 
2 Nurden AT. Should studies on Glanzmann thrombasthenia not be telling us more about cardiovascular disease and other major illnesses? Blood Rev 2017;31(05):287-299

3 Solh T, Botsford A, Solh M. Glanzmann's thrombasthenia: pathogenesis, diagnosis, and current and emerging treatment options. J Blood Med 2015;6:219-227

4 Poon MC, Di Minno G, d'Oiron R, Zotz R. New insights into the treatment of Glanzmann thrombasthenia. Transfus Med Rev 2016;30(02):92-99

5 Poon MC, d'Oiron R. Alloimmunization in congenital deficiencies of platelet surface glycoproteins: focus on Glanzmann's thrombasthenia and Bernard-Soulier's Syndrome. Semin Thromb Hemost 2018;44(06):604-614

6 Siddiq S, Clark A, Mumford A. A systematic review of the management and outcomes of pregnancy in Glanzmann thrombasthenia. Haemophilia 2011;17(05):e858-e869

7 Bellucci S, Caen J. Molecular basis of Glanzmann's thrombasthenia and current strategies in treatment. Blood Rev 2002;16(03): 193-202

8 Vamvakas EC, Blajchman MA. Blood still kills: six strategies to further reduce allogeneic blood transfusion-related mortality. Transfus Med Rev 2010;24(02):77-124

9 Carson JL, Guyatt G, Heddle NM, et al. Clinical practice guidelines from the AABB: red blood cell transfusion thresholds and storage. JAMA 2016;316(19):2025-2035

10 European Medical Agency. NovoSeven EPAR assessment report. Available at: https://www.ema.europa.eu/en/documents/variation-report/novoseven-h-c-000074-ii-0104-epar-assessment-report-variation_en.pdf. Accessed July 2020

11 Poon MC, d'Oiron R, Zotz RB, Bindslev N, Di Minno MN, Di Minno G. Glanzmann Thrombasthenia Registry Investigators. The international, prospective Glanzmann Thrombasthenia Registry: treatment and outcomes in surgical intervention. Haematologica 2015;100(08):1038-1044

12 Di Minno G, Zotz RB, d'Oiron R, Bindslev N, Di Minno MN, Poon MC. Glanzmann Thrombasthenia Registry Investigators. The international, prospective Glanzmann Thrombasthenia Registry: treatment modalities and outcomes of non-surgical bleeding episodes in patients with Glanzmann thrombasthenia. Haematologica 2015;100(08):1031-1037

13 Poon MC, D’Oiron R, Von Depka M, et al; International Data Collection on Recombinant Factor VIla and Congenital Platelet Disorders Study Group. Prophylactic and therapeutic recombinant factor VIIa administration to patients with Glanzmann's thrombasthenia: results of an international survey. J Thromb Haemost 2004;2(07):1096-1103

14 Chitlur MEN, Kraut EH, Cooper DL. Recombinant factor VIla (rFVIIa) use in glanzmann's thrombasthenia (GT) and other platelet disorders (OPDS): hemophilia and thrombosis research society (HTRS) registry data (abstract). J Thromb Haemost 2011;9 (Suppl 02):340

15 Bomke BHT, Dücker C, Scharf RE. Platelet-free hemotherapy in patients with Bernard Soulier syndrome (BSS) and Glanzmann's thrombasthenia (GT): successful bleeding prophylaxis with recombinant Factor VIIa (rFVIIa) for elective surgery (abstract). Hamostaseologie 2010;30:A26
16 Bowles L, Pasi J, Hart D, et al. Ovarian endometrioma in two women with Glanzmann's thrombasthenia (abstract). Haemophilia 2012;18(Suppl 03):203-204

17 Ceglarek B, Sikorska A, Bykowska K, et al. Effective therapy with recombinant factor VIIa in female patient suffering from Glanzmann thrombasthenia - the own experience (abstract). Acta Haematol Pol 2015;46S:88

18 Elshinawy M, Al-Rawas A, Wali Y. Coexistence of Glanzmann's thrombasthenia and maple syrup urine disease (MSUD): Implications for hemostatic management (abstract). Haematologica 2017;102(Suppl 2):839

19 Gunes AM, Evim MS, Birol B. The use of recombinant FVIIa in two children with Glanzmann's thrombasthenia with severe bleeding after trauma: po-tu-162 (abstract). Haemophilia 2012;18(Suppl 03):148

20 Poon MC, Demers C, Jobin F, Wu JW. Recombinant factor VIIa is effective for bleeding and surgery in patients with Glanzmann thrombasthenia. Blood 1999;94(11):3951-3953

21 Staritz P, Zimmermann R, Domschke C, et al. Successful IVF and pregnancy in Glanzmann's thrombasthenia under cover of recombinant factor VIIa: Po 355 (abstract). J Thromb Haemost 2013; 11(Suppl 02):1153-1154

22 Tsakiris DA, Graf L, Brunner S, et al. Successful ankle replacement in a patient with Glanzmann thrombasthenia: a case report: 80 (abstract). Haemophilia 2012;18(Suppl 01):49-50

23 Valentino LA. Use of rFVIIa in 4 children with Glanzmann thrombasthenia. J Pediatr Hematol Oncol 2006;28(10):653-658

24 Ward J, Maddox J, Kerr R. Glanzmann thrombasthaenia - a single centre experience of different therapeutic approaches to achieve haemostasis in 3 patients (abstract). Haemophilia 2010;16(Suppl 04):123

25 Nunez R, Perez-Garrido R. Recombinant factor VIIa is effective for bleeding and surgery in patients with Glanzmann Thrombasthenia (abstract). J Thromb Haemost 2009;7(Suppl 02):888

26 van Buuren HR, Wielenga JJ. Successful surgery using recombinant factor VIIa for recurrent, idiopathic nonulcer duodenal bleeding in a patient with Glanzmann's thrombasthenia. Dig Dis Sci 2002;47(09):2134-2136

27 d'Oiron R, Ménart C, Trzeciak MC, et al. Use of recombinant factor VIIa in 3 patients with inherited type I Glanzmann's thrombasthenia undergoing invasive procedures. Thromb Haemost 2000; 83(05):644-647

28 Poon M-C, Di Minno G, Zotz R, et al. Glanzmann's thrombasthenia: strategies for identification and management. Expert Opin Orphan Drugs 2017;5(08):641-653

29 European Medical Agency. NovoSeven summary of product characteristics. Available at: https://www.ema.europa.eu/en/documents/product-information/novoseven-epar-product-information_en.pdf. Accessed September 19, 2020

30 Zotz RB, Poon MC, Di Minno G, D’Oiron R. Glanzmann Thrombasthenia Registry Investigators. The international prospective Glanzmann Thrombasthenia Registry: pediatric treatment and outcomes. TH Open 2019;3(03):e286-e294

31 Neufeld EJ, Négrier C, Benchikh El Fegoun S, Cooper DL, Rojas-Rios A, Seremetis S. Recombinant activated factor VII in approved indications: Update on safety. Haemophilia 2018;24(04):e275-e277 